\title{
A QUALIDADE NA SAÚDE COMPREENDIDA SOB A ÓTICA DOS SEUS SINAIS: UM ESTUDO DE CASO EM UMA CLÍNICA DE TRATAMENTO ONCOLÓGICO
}

\section{THE QUALITY OF HEALTH UNDERSTOOD UNDER THE PERSPECTIVE OF CLUES: A CASE STUDY IN A CLINICAL OF ONCOLOGIC TREATMENT}

\author{
Antônio Carlos Rodrigues ${ }^{1}$; Noel Torres Júnior ${ }^{2}$ \\ ${ }^{1}$ Universidade Federal de Minas Gerais - UFMG - Belo Horizonte - Brasil \\ tonimacr@gmail.com \\ ${ }^{2}$ Universidade Federal de Minas Gerais - UFMG - Belo Horizonte - Brasil \\ noel@face.ufmg.br
}

\begin{abstract}
Resumo
Cada cliente constrói uma experiência de serviço que pode ser decomposta por uma série de outras pequenas experiências. Cada uma delas transmite inúmeras mensagens que impactam a forma como os clientes se sentem em relação ao serviço entregue. Essas mensagens podem ser compreendidas como vários "Sinais da Qualidade" que são percebidos pelos clientes durante e após a entrega do serviço. Tendo como referência a importância destes sinais para entrega de um serviço de qualidade, este trabalho busca compreender como os Sinais da Qualidade são construídos em organizações de saúde que notadamente trabalham com elevados padrões de qualidade. Nesta direção, o trabalho analisou diversas ações realizadas pelos gestores $e$ funcionários de uma clínica de tratamento oncológico de destaque setorial para criação destes sinais. O estudo apontou a importância dos Sistemas de Gestão da Qualidade para a criação de sinais funcionais, importantes para a confiabilidade dos serviços. Entretanto, constatou-se que a criação de sinais mecânicos e humanos foram frutos de iniciativas da empresa que transpassaram, em grande parte, os requisitos dos Sistemas de Gestão implementados.
\end{abstract}

Palavras-chave: sinais da qualidade; qualidade em saúde; qualidade.

\section{Introdução}

Em grande parte dos países desenvolvidos, o setor de serviços cresceu significativamente no século XX. Sua importância é evidenciada pelo fato de ser um segmento econômico relevante e com grande crescimento em diversos países (CHASE; APTE, 2007; FITZSIMMONS; FITZSIMMONS, 2010; LOVELOCK; WIRTZ, 2008; ZEITHAML; BITNER; GREMLER, 2011). A maior parcela do crescimento absoluto nas estatísticas de nível de emprego e da aceleração do aumento do número de vagas geradas mundialmente pelos serviços se concentra, sobretudo, no setor de serviços de saúde (ZEITHAML; BITNER; GREMLER, 2011). 
Nesta direção, a Organização Mundial da Saúde (2010) alega que os gastos nessa rubrica foram de 9,7\% do Produto Interno Bruto (PIB) do planeta em 2009, um valor estimado em US\$5,3 trilhões. Nos Estados Unidos, tais despesas correspondiam a 15,7\% do PIB. No Brasil, o segmento também é bastante significativo, representando o equivalente a 8,4\% do PIB (PEDROSO; MALIK, 2011).

A necessidade de cuidados, investimentos e gastos com saúde tende a aumentar gradativamente ao longo do tempo. Vários fatores explicam esta tendência de crescimento. Vale citar alguns deles: uma maior conscientização por parte dos indivíduos de que devem se cuidar melhor; a maior disponibilidade de recursos tecnológicos para este setor; o aumento do poder de renda e, consequentemente, de acesso a estes serviços pela população; e, finalmente, a elevação da expectativa de vida. Além dessas questões econômicas, as atividades de saúde envolvem o cuidar da vida humana, o que as torna extremamente críticas para a sociedade (PEDROSO; MALIK, 2011).

Soma-se a isto, o fato de que a prestação de serviços de saúde apresenta certas peculiaridades, uma vez que os serviços desta natureza podem ser caraterizados como complexos, dispendiosos e universalmente utilizados, com impactos na qualidade de vida diária da população (BERRY; BENDAPUDI, 2007).

Dado o tamanho, a relevância e o impacto que tal setor apresenta na sociedade, torna-se importante o desenvolvimento de pesquisas por acadêmicos de marketing e operações de serviços neste segmento. Contudo, poucos estudos têm sido realizados envolvendo a combinação destas duas disciplinas. Este enfoque pode proporcionar uma análise mais completa dos fenômenos que ocorrem neste campo, auxiliando no desenvolvimento de estratégias que elevem os níveis de segurança e qualidade dos serviços (CHASE; STEWART, 1994; BERRY; BENDAPUDI, 2007).

Nesse contexto, a despeito do grande desenvolvimento do tema Qualidade na área industrial, a compreensão deste tema para o setor de saúde pode ser entendida como relevante. Notadamente, poucos trabalhos abordam de maneira aprofundada a forma como a Gestão da Qualidade deve ser implantada e conduzida nas organizações de serviços (CHASE; STEWART, 1994). Na sua maioria, os trabalhos acerca da Qualidade em serviços se voltam para a mensuração da Qualidade baseados no modelo seminal SERVQUAL proposto pelos autores Parasuraman, Zeithaml e Berry (1988).

Consoante como a necessidade de maior entendimento do tema Qualidade para o setor de saúde, os trabalhos de Carbone e Haeckel (1994), Carbone (2004), Berry, Wall e Carbone (2006), Berry e Carbone (2007), Berry e Seltman (2010) analisam a construção da percepção da qualidade pelo cliente do serviço entregue pelo prestador. Na visão destes trabalhos, todo cliente constrói uma experiência de serviço ao interagir com uma organização, seja pessoalmente, por telefone, internet ou outros meios. Tal experiência pode ser decomposta por uma série de outras pequenas experiências. Cada uma delas transmite inúmeras mensagens que impactam a forma como os 
clientes se sentem em relação ao serviço entregue. Essas mensagens podem ser compreendidas como vários "sinais" que são percebidos pelos clientes durante e após a entrega do serviço. De certo modo, eles contam uma "história do serviço" entregue que são inerentes à própria experiência de serviço vivenciada pelo cliente.

Dentro da perspectiva de sinais, torna-se relevante que os gestores tenham o conhecimento acerca da "história do serviço" criada em seus clientes pela organização. A mesma deve ter o cuidado de construir uma "história do serviço" que seja certa e congruente com os seus objetivos organizacionais. Portanto, pode-se afirmar que é melhor para a organização contar uma "história do serviço" que seja consistente, coesa e atraente do que uma inconsistente, incoerente e desinteressante (BERRY; WALL; CARBONE, 2006).

Além disso, verificou-se uma baixa produção acadêmica de trabalhos oriundos da área de Gestão de Operações e Engenharia de Produção acerca de qualidade de serviços no setor de saúde brasileiro. Este fato foi um elemento motivador para o desenvolvimento deste trabalho, uma vez que os autores vislumbraram a oportunidade de estudar um assunto ainda pouco conhecido, mas capaz de fomentar novas discussões sobre este tema.

Diante destas considerações, o presente trabalho tem como objetivo compreender como os Sinais da Qualidade sob a perspectiva dos autores Berry, Carbone, Haeckel, Wall e Seltman são construídos nas Organizações de Saúde que notadamente trabalham com elevados padrões de qualidade. Para tanto, realizou-se um estudo de caso único em uma empresa do setor de saúde com notada excelência na prestação de seus serviços.

\section{Referencial teórico}

\subsection{Características dos serviços de saúde}

\subsubsection{Similaridades entre serviços de saúde e outros serviços}

Os serviços de saúde refletem diversas características igualmente associadas a outros tipos de serviços (BERRY; BENDAPUDI, 2007). Na maioria dos casos, eles são essencialmente intangíveis, pois os principais benefícios do diagnóstico, do tratamento e da educação médica do paciente derivam principalmente de atos desempenhados pelos funcionários em um processo. Assim, os pacientes incorrem em gastos monetários que não objetivam primordialmente a aquisição de bens tangíveis. Nesse sentido, o tratamento médico em si, frequentemente, combina serviços intangíveis suportados por bens (por exemplo, uma sala de cirurgia equipada) e bens apoiados por serviços intangíveis (por exemplo, produtos e serviços farmacêuticos).

Os serviços de saúde são intensivos tanto em trabalho manual quanto em habilidades. A forte existência destes dois elementos contribui para a ocorrência da variabilidade no desempenho 
de um profissional para outro. Em que se pese a variabilidade devido ao tipo de serviço, as habilidades de comunicação e técnicas dos profissionais.

Pelo fato dos serviços de saúde serem fornecidos às pessoas, e não aos seus bens físicos, a produção e o consumo são simultâneos. É necessário que o paciente esteja fisicamente presente onde o serviço é prestado (por exemplo, um consultório médico ou um hospital) e no momento em que médicos, enfermeiros e outros profissionais estejam disponíveis para prestar o serviço. Em certos casos, a simultaneidade pode ser um complicador para pacientes com idade avançada, dificuldade de locomoção ou situados em local de difícil acesso. Além disso, muitas das vezes, os pacientes esperam longos períodos para recebimento do atendimento.

Como muitos serviços, o serviço de saúde é perecível. As organizações de saúde criam valor com base em tempo e experiência do pessoal, equipamentos e espaço físico. Quando esses recursos não são utilizados, o valor que poderia ter sido criado perece.

Similarmente ao uso de outros serviços técnicos, como de reparo e avaliação de equipamentos eletrônicos, os clientes se encontram em considerável desvantagem de conhecimento acerca do próprio serviço entregue. Isto por sua vez, torna a qualidade clínica de difícil apreciação para o paciente mesmo após a execução do serviço. Dessa forma, os pacientes avaliam as experiências de serviços com base em comportamentos interpessoais dos profissionais, ao invés de avaliarem as habilidades técnicas dos mesmos. Assim, apesar de claramente vital para os pacientes, a qualidade técnica é de difícil mensuração (BENDAPUDI, NEELI et al, 2006).

\subsubsection{Dissimilaridades entre serviços de saúde e outros serviços}

A despeito de serem semelhantes a outros serviços, os serviços de saúde apresentam características peculiares. As subseções a seguir destacam algumas diferenças que merecem uma maior atenção pelo gestor.

\subsubsection{Os clientes são enfermos}

Os clientes de serviços de saúde estão doentes, podem estar estressados, e, às vezes, devem permanecer por algum tempo na "fábrica" de serviços - uma vez que eles são pacientes. Servir pacientes com alguma combinação de doença, dor, incerteza e medo representa um desafio único para os prestadores de serviços de saúde (BERRY; BENDAPUDI, 2007). Essas circunstâncias levam os pacientes a serem mais exigentes, sensíveis e/ou dependentes do que normalmente seriam em outros tipos de serviço. As emoções influenciam a capacidade de escolha dos pacientes. Assim, elevados níveis de ansiedade, induzidos por estresse, podem desencadear preferências por opções mais seguras às quais fornecem maior sensação de controle. Por outro lado, quando os pacientes experimentam situações de tristeza eles tendem a preferir opções mais gratificantes e reconfortantes (RAGHUNATHAN; PHAM; CORFMAN, 2006). Além disso, os pacientes, muitas vezes, são 
propensos a experimentar uma mescla de emoções, como a esperança de cura de uma doença por meio de uma intervenção cirúrgica, alternada pelo medo de que algo dê errado durante tal procedimento (BERRY; MIRABITO; BERWICK, 2004).

\subsubsection{Os clientes são relutantes}

A presença de alguma doença, ou a possibilidade dela ocorrer, faz com que as pessoas assumam papel de consumidores dos serviços de saúde. Geralmente, o contato inicial ocorre por meio de exames médicos e procedimentos cirúrgicos, muitas vezes, a contragosto e com certo receio por parte do paciente. A literatura sobre serviços em sua grande maioria concentra-se nos serviços que os clientes "desejam” (como recreação, entretenimento, cuidados pessoais e serviços de comunicações). Menor atenção é dedicada ao estudo dos serviços que os clientes precisam, mas não necessariamente "desejam" (BERRY; BENDAPUDI, 2007). A aversão do cliente afeta a percepção de qualidade de serviço e, consequentemente, o grau em que os clientes aceitam o papel de "coprodutor", necessário para um resultado positivo (BENDAPUDI; LEONE, 2003). Desempenhos aceitáveis dos serviços de saúde, normalmente, requerem a cooperação do paciente, tanto no encontro (respondendo a perguntas do clínico honestamente) quanto depois (tomando as medicações prescritas). A coprodução do cliente pode envolver emoções, custos e mudanças de estilo de vida. Nesse contexto, na maioria das vezes, o desinteresse dos pacientes em colaborar para coprodução do serviço decorre do sentimento de perda de controle sobre os resultados (BENDAPUDI; LEONE, 2003; DUHACHEK, 2005).

\subsubsection{Os clientes renunciam a privacidade}

Os serviços de saúde são inerentemente pessoais, mas não necessariamente imbuídos de privacidade. Outros serviços não exigem que os clientes se desnudem física e emocionalmente assim como os serviços de saúde. Assim sendo, para receber o melhor cuidado possível, os pacientes não só têm que se despir, mas também discutir assuntos muito pessoais com pessoas “estranhas". Além disso, os prestadores de serviços de saúde, muitas das vezes, são obrigados a informar os seus pacientes que eles devem perder peso, parar de dirigir um carro ou parar de tomar bebida alcoólica (BERRY; BENDAPUDI, 2007).

\subsubsection{Os clientes precisam de atendimento "holístico"}

Serviços de saúde precisam ser personalizados para atender às condições médicas do paciente, considerando-se a idade, a condição mental, as características pessoais, as preferências, as circunstâncias familiares e a capacidade financeira. A prestação de serviço de qualidade depende não só da capacidade técnica dos profissionais, mas também do conhecimento das individualidades 
dos pacientes. Neste sentido, o tratamento a ser aplicado ao paciente deve ser concebido sob uma perspectiva holística (BERRY; BENDAPUDI, 2007).

\subsubsection{Os clientes correm risco}

São poucos os serviços em que os clientes correm riscos. Os serviços de saúde são um deles (BERRY; BENDAPUDI, 2007). Uma profissão que supostamente busca a cura pode prejudicar irreversivelmente o paciente (BURKE, 2003). Embora nem todos os tipos de infecções sejam evitáveis, algumas podem ser erradicadas por meio de práticas de segurança, tais como: higiene adequada das mãos, elevação da cabeceira da cama para que os pacientes em respiradores mecânicos possam reduzir suas chances de contrair doenças respiratórias, administração de antibióticos adequados antes da cirurgia e posicionamento dos pacientes em quartos individuais, para evitar a exposição de agentes infecciosos provenientes de companheiros de quarto (BURKE, 2003; BERRY; MIRABITO; BERWICK, 2004; BERRY; BENDAPUDI, 2007).

Milhões de pacientes são prejudicados por erros de medicação (KOHN; CORRIGAN; DONALDSON, 2000). Erros deste tipo incluem a administração de doses ou a combinação de medicamentos incorreta. A quantidade de medicamentos administrados, o número de profissionais que prestam serviços para diversos pacientes e medicamentos com nomes similares podem ser fontes de possíveis equívocos. Prescrições escritas manualmente figuram como outra fonte de erros. A aplicação de códigos de barra e de sistemas de informações para a administração de medicamentos pode diminuir significativamente a incidência de erros de medicação. Erros de comunicação também contribuem para erros no diagnóstico e tratamento dos pacientes. Um estudo envolvendo 75 relatórios de erro de 18 médicos em cinco estados americanos constatou que 80\% dos erros aconteceram devido a falhas de comunicação, tais como falta de informação nos prontuários ou registros, má comunicação entre os clínicos e má gestão de pedidos dos pacientes (WOOLF et al, 2004; BERRY; BENDAPUDI, 2007).

Os prejuízos para os pacientes, no entanto, nem sempre são tão evidentes como aqueles decorrentes de falhas cirúrgicas ou erros de medicação. Kahn e Luce (2003) conduziram um experimento com mulheres que se submeteram a exames de mamografia. Apurou-se que aquelas pacientes que receberam um alarme falso tiveram maiores níveis de estresse, bem como ficaram menos propensas à realização de futuras mamografias do que mulheres do grupo de controle que receberam os resultados normais. Contudo, ao mesmo tempo, a redução de futuros exames não ocorreu em pacientes que receberam alarme falso, mas receberam a informação de que resultados positivos na mamografia não indicam necessariamente câncer de mama.

\subsubsection{Os prestadores de serviços estão sob estresse}


A prestação de serviços doentes é um trabalho extremamente estressante. Profissionais da enfermagem chegam a trabalhar em turnos de doze horas ou mais, quase ininterruptamente. Eles ficam de pé grande parte do tempo realizando trabalho "pesado", como levantar ou virar os pacientes ou ajudá-los no banheiro, podendo andar vários quilômetros durante a coleta de medicamentos e suprimentos necessários (HENDRICH; FAY; SORRELLS, 2002). Um médico pode terminar sua jornada de trabalho "regular" visitando de 25 a 40 pacientes, atendendo dezenas de telefonemas e podendo ser, ainda, solicitado no meio da noite por algum paciente com dificuldades (BERRY; BENDAPUDI, 2007). O esforço físico e a intensidade emocional pelos quais passam os cirurgiões, por exemplo, são notavelmente espantosas. Perder a concentração por um momento pode prejudicar o paciente irreversivelmente. Não obstante a grande possibilidade de ocorrência da fadiga, suas consequências negativas são inaceitáveis nos procedimentos médicos. A exaustão emocional dos profissionais de serviços de saúde no local de trabalho é resultado da frequência, da duração e da intensidade e variedade de exposição emocional. Muitos profissionais apresentam níveis elevados de cada uma dessas dimensões. O estresse emocional é inerente ao atendimento de pessoas gravemente doentes, fato que contribui para aumentar o estresse físico no trabalho (MORRIS; FELDMAN, 1996).

A possibilidade ou ocorrência real da negligência médica é outra fonte de estresse dos profissionais de saúde. A literatura de qualidade de serviço salienta a importância da confiabilidade e da recuperação das falhas (PARASURAMAN; ZEITHAML; BERRY, 1988). Os erros médicos são comuns, entretanto, sua recuperação é de difícil concretização, pois existe possibilidade de prejuízos irreversíveis aos pacientes. A prática recomendada na literatura padrão de recuperação de serviços é o pedido de desculpas aos clientes. Apesar disso, não é o que frequentemente ocorre nos serviços de saúde, a maioria dos profissionais pensa em pedir desculpas por um erro, mas fica receosa quanto às consequências de tais declarações fato que poderia deixá-los vulneráveis legalmente (GALLAGHER et al, 2003).

Outra fonte de estresse emocional para os médicos é o momento de informar más notícias aos pacientes. Outros tipos de prestadores de serviços entregam más notícias aos clientes de uma maneira mais tranquila, são exemplos: em uma companhia área - “o voo está atrasado" ou em uma loja - "o produto vendido está esgotado". Entretanto na área de saúde, as informações passadas podem ser extremamente impactantes para os clientes. Informar a um paciente de que ele agora é paralítico devido a um acidente vascular cerebral ou que ele possui uma doença terminal, não é uma tarefa fácil. Além disso, os pacientes diferem em quanto realmente querem saber sobre o seu prognóstico. Muitas vezes, estes podem ser vagos em transmitir o que eles querem saber. Esses tipos de situações são diferentes do que os estudos relatam na literatura tradicional. Na prestação de 
serviços de saúde, a má notícia é, geralmente, mais frequente e as relações entre profissionais da saúde e pacientes muito mais pessoal e delicada (BERRY; BENDAPUDI, 2007).

\subsection{Sinais da qualidade}

Pequenos detalhes na prestação de serviços podem ser de vital importância para a organização (BERRY; WALL; CARBONE, 2006). Enquanto grande parte dos gestores concentrase em alcançar metas maiores, maior atenção a detalhes da prestação de serviço pode resultar em maior nível de satisfação do cliente. Pequenos sinais podem demonstrar que o serviço é excepcional, promovendo um efeito proporcionalmente maior sobre a forma como o cliente avalia a experiência do serviço em si (BERRY; WALL; CARBONE, 2006; BERRY; SELTMAN, 2010). A experiência de um cliente em um hotel, por exemplo, não está relacionada apenas às expectativas básicas, como ter suas reservas feitas, quartos limpos e serviço de quarto entregue a tempo, mas também sinais sutis, como textura do lençol, decoração do ambiente e atitude da recepcionista.

Quando seleciona e utiliza os serviços que adquire, o cliente observa mais e processa mais informação do que os gestores e prestadores de serviços costumam imaginar (BERRY; BENDAPUDI, 2007; BERRY; SELTMAN, 2010). Ele age como detetive, no sentido de que processa e organiza os sinais da experiência com base em um conjunto de impressões que evocam sentimentos (BERRY; WALL; CARBONE, 2006; CARBONE, 2004; HAECKEL; CARBONE; BERRY, 2003). Ele processa esses sinais ao decidir entre comprar ou não um determinado serviço e ao avaliá-lo no momento em que o está recebendo e depois.

A principal fonte de criação de valor para um serviço é o desempenho ofertado pela empresa para o consumidor (BERRY; WALL; CARBONE, 2006). Quando o cliente compra serviços, este não compra propriedade ou posse de objetos. Ao comprar um bilhete de transporte aéreo, alugar um carro, fazer uma reserva em um hotel, ir a um restaurante e utilizar outros serviços durante uma viagem turística, ele traz pouco ou nada de tangível para sua casa.

Os serviços, em geral, apresentam um número mais elevado de experiências do que os bens manufaturados (BERRY; WALL; CARBONE, 2006; BERRY; CARBONE, 2007). O consumidor de bens, normalmente, não visita o local onde as mercadorias são feitas. Entretanto, os consumidores de serviços, na grande maioria das vezes, não só visitam como podem permanecer no local onde os serviços são prestados.

Assim, a experiência com bens manufaturados é bem mais restrita do que a com os serviços. Numa viagem de avião, o indivíduo é colocado em pelo menos três "fábricas de serviços": o embarque, o avião e o desembarque. Em cada uma dessas fábricas, o cliente experimenta as instalações, os equipamentos e interage com diversos prestadores de serviços. Uma viagem aérea pode envolver um complexo conjunto de experiências concentrados em apenas algumas horas. 
Existem, portanto, vários momentos que podem levar o passageiro a sentir vários tipos de sentimentos como satisfação, decepção, frustração ou fúria (BERRY; LAMPO, 2004). Uma viagem de avião, desse modo, envolve uma torrente de sinais, os quais precisam ser gerenciados.

Ao interagir com organizações o cliente, conscientemente ou não, filtra os sinais recebidos e os organizam em um conjunto de impressões, algumas racionais e outras de caráter mais emocional (BERRY; WALL; CARBONE; 2006; BERRY; SELTMAN, 2010). Logo, tudo quanto seja percebido - ou que seja evidente em sua ausência - constitui um sinal da experiência. A Figura 1 retrata este fato.

Figura 1 - Os sinais advêm de todas as coisas que os clientes sentem

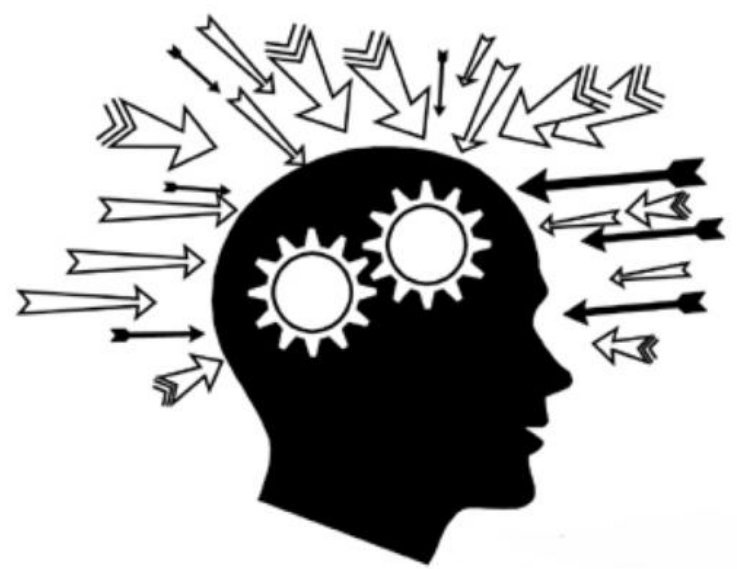

Fonte: Adaptada de Carbone (2004)

Tudo que o cliente pode ver, ouvir, cheirar, sentir o gosto e tocar é um sinal (CARBONE, 2004; BERRY; CARBONE, 2007; BERRY; WALL; CARBONE, 2006; BERRY; SELTMAN; 2010). Por exemplo, tudo em uma mesa de restaurante potencialmente comunica uma sinal para os clientes, incluindo a aparência e o conteúdo do cardápio, a toalha de mesa, a utilização de guardanapos de papel ou de pano, limpeza da mesa e, naturalmente, a apresentação e sabor dos alimentos. Uniforme, comportamento e linguagem dos garçons também são considerados sinais que fazem a experiência do serviço. Os sinais percebidos pelos consumidores contam a história de serviços de uma organização de maneira poderosa. As organizações bem-sucedidas que se notabilizam pela excelência de seus serviços contam suas histórias de maneira eficiente mediante o adequado gerenciamento de sinais. Logo, é melhor contar uma história consistente, coesa e atraente do que uma inconsistente, incoerente e desinteressante (BERRY; SELTMAN; 2010).

Os sinais podem ser divididos em três categorias principais: funcionais, mecânicos e humanos (BERRY; WALL; CARBONE, 2006; BERRY; BENDAPUDI, 2007; BERRY; SELTMAN, 2010; CARBONE, HAECKEL, 1994; CARBONE, 2004; HAECKEL; CARBONE; BERRY, 2003). 
Quadro 1 - Os três tipos de sinais

\begin{tabular}{ccc}
\hline Sinais & Emitidos por & Interpretação \\
\hline Funcionais & Bens e serviços & Racional \\
Mecânicos & Ambiente dos serviços & Emocional \\
Humanos & Fornecedores dos serviços & Emocional \\
\hline
\end{tabular}

Fonte: Adaptado de Berry e Carbone (2007)

Conforme o Quadro 1, os sinais mecânicos provêm de objetos reais ou do ambiente. Envolvem pistas sobre a apresentação sensorial do serviço. Incluem percepções visuais, cheiros, sons, sabores e texturas. Os sinais funcionais dizem respeito à confiabilidade do serviço. Os sinais humanos emergem do comportamento e da aparência dos prestadores de serviços - tom de voz, nível de entusiasmo, linguagem corporal, limpeza e vestuário adequado (CARBONE, 2004; BERRY; CARBONE, 2007; BERRY; WALL; CARBONE, 2006; BERRY; SELTMAN; 2010).

\subsection{Sistemas de gestão da qualidade}

A qualidade percebida pelo cliente relaciona-se com os bens e serviços entregues pela organização. Ela pode ser construída mediante a adoção de Sistemas de Gestão.

A norma de Gestão da Qualidade mais difundida é a série ISO 9000. Esta é composta pelas normas ISO 9000 (sistema de gestão da qualidade fundamentos e vocabulários), ISO 9001 (sistema de gestão da qualidade - requisitos) e ISO 9004 (sistema de gestão da qualidade - diretriz para melhoria de desempenho). A certificação é feita apenas com base na norma ISO 9001, sendo as duas outras para orientação.

A despeito de algumas críticas acerca da série ISO 9000 no que tange ao aumento da burocracia e número de documentos, esta norma tem induzido à melhoria contínua em várias atividades conduzidas pelas empresas. A adequada implementação da norma traz vários benefícios. São exemplos: maior racionalização no uso de insumos; maior controle dos processos produtivos com a consequente redução do desperdício; e maior conscientização da mão de obra em relação à importância do trabalho (CARVALHO; PALADINI, 2006).

As normas ISO 9000 podem ser implementadas em qualquer setor e para qualquer tipo de organização. Entretanto o setor de saúde apresenta algumas especificidades que não estão contempladas por normas gerais de Sistemas de Gestão da Qualidade, como a própria Série ISO 9000. Diante deste problema, o setor de saúde criou um sistema próprio de acreditação denominado de Acreditação Hospitalar (AH). Este se iniciou no Brasil a partir dos anos 90, com a publicação “Acreditação de Hospitais para a América Latina e Caribe" (PAGANINI; NOVAES, 1992). Posteriormente, algumas iniciativas estaduais surgiram nesta direção. Em seguida, estas iniciativas foram articuladas pelo Ministério da Saúde que, em 1995, por meio do Programa Brasileiro de Qualidade e Produtividade (PBQP), implementou a Acreditação Hospitalar no Brasil. Em 1998 ocorreu à primeira edição do Manual Brasileiro de Acreditação Hospitalar (MBAH). Em 2001, o 
Ministério da Saúde considerou como uma política pública a adoção de medidas que possibilitem implantar e garantir a qualidade da assistência nos hospitais brasileiros.

A Acreditação Hospitalar (AH) constitui uma metodologia pautada na racionalização, na melhoria da organização dos hospitais e na busca de educação permanente do pessoal de serviço e dos seus líderes. A AH está fundamentada em padrões de referências desejáveis construídos por peritos da área que estabelecem critérios, indicadores e instrumentos para a avaliação do grau de concordância das práticas executadas pela organização avaliada com estes padrões (ORGANIZAÇÃO, 2013).

A Organização Nacional de Acreditação (ONA) é uma organização privada, sem fins lucrativos e de interesse coletivo, que tem como principal objetivo a melhoria da qualidade de assistência médica (ORGANIZAÇÃO, 2013). A missão da ONA é a promoção de um processo de Acreditação, visando aprimorar a qualidade da assistência na área da saúde no Brasil (ANTUNES, 2002). Ela é responsável pelo estabelecimento de padrões e pelo monitoramento do processo de Acreditação realizado pelas instituições acreditadoras.

O Programa Brasileiro de Acreditação Hospitalar (PBAH), por sua vez, visa ao amplo entendimento de um processo permanente de melhoria da qualidade assistencial, mediante a Acreditação periódica da rede hospitalar pública e privada. Para tanto, instituiu no âmbito hospitalar mecanismos para autoavaliação e aprimoramento contínuo da qualidade da atenção médicohospitalar.

Na lógica do Processo de Acreditação (PAc), não se avalia um serviço ou departamento isoladamente. Entende-se que as estruturas e processos do hospital são de tal ordem interligados que o funcionamento de um componente interfere em todo o conjunto e no resultado final (PAGANINI; NOVAES, 1992).

Quadro 2 - Princípios de cada nível de certificação

\begin{tabular}{|c|c|c|}
\hline Nível & Princípio específico & Descrição \\
\hline 1 & Segurança & $\begin{array}{l}\text { As exigências deste nível contemplam o atendimento aos requisitos básicos da } \\
\text { qualidade na assistência prestada ao cliente, nas especialidades e nos serviços da } \\
\text { organização de saúde a ser avaliada, com recursos humanos compatíveis com a } \\
\text { complexidade, qualificação adequada (habilitação) dos profissionais e responsáveis } \\
\text { técnicos com habilitação correspondente para as áreas de atuação institucional. }\end{array}$ \\
\hline 2 & Segurança e organização & $\begin{array}{l}\text { As exigências deste nível contemplam evidências de adoção do planejamento na } \\
\text { organização da assistência, referentes à documentação, corpo funcional (força de } \\
\text { trabalho), treinamento, controle, estatísticas básicas para a tomada de decisão } \\
\text { clínica e gerencial, e práticas de auditoria interna. }\end{array}$ \\
\hline 3 & $\begin{array}{c}\text { Segurança, organização e } \\
\text { práticas de gestão de } \\
\text { qualidade }\end{array}$ & $\begin{array}{l}\text { As exigências deste nível contêm evidências de políticas institucionais de melhoria } \\
\text { contínua em termos de: estrutura, novas tecnologias, atualização técnico- } \\
\text { profissional, ações assistenciais e procedimentos médicos-sanitários. Evidências } \\
\text { objetivas de utilização da tecnologia da informação, disseminação global e } \\
\text { sistêmica de rotinas padronizadas e avaliadas com foco na busca da excelência. }\end{array}$ \\
\hline
\end{tabular}

Fonte: Adaptado de Organização Nacional de Acreditação (2013) 
As Instituições Acreditadoras (IAC) são entidades de direito privado, credenciadas pela ONA para desenvolverem o Processo de Avaliação (PAv) das Organizações Prestadoras de Serviços de Saúde (OPSS). O Processo de Avaliação é conduzido por uma equipe de avaliadores que deve ser composta de no mínimo, três membros, sendo: um médico, um enfermeiro e um administrador. O Processo de Acreditação se estrutura por níveis 1, 2 e 3, com seus devidos princípios norteadores. O Quadro 1 apresenta uma breve descrição dos princípios norteadores de cada nível de certificação.

\section{Metodologia}

A escolha da organização pesquisada foi selecionada por seu caráter representativo (YIN, 2005). Para tanto, considerou-se, sua inclusão na categoria teórica: prestadora privada de serviço ambulatorial e/ou pronto-atendimento com notada excelência na prestação de seus serviços e com sede na região metropolitana de Belo Horizonte. Optou-se por um estudo de caso único, visto que o trabalho busca compreender em maior profundidade o fenômeno estudado (EISENHARDT, 1989). A entidade analisada será aqui denominada de Clínica Alfa.

A coleta de dados foi realizada, principalmente, por meio de entrevistas semiestruturadas. Os entrevistados foram aqueles que Bryman (1989) denomina informantes chaves da organização. Estes são funcionários com senioridade e capacidade para a tomada de decisões e execução de ações voltadas para a qualidade na entrega dos serviços oferecidos pela organização. A escolha destes deu-se pela indicação da Diretora Administrativa da organização, uma vez que são pessoas diretamente ligadas ao principal processo de entrega do serviço da organização.

O convite aos entrevistados foi formalizado por meio de mensagem eletrônica à direção da empresa selecionada. O agendamento das entrevistas foi realizado pelo próprio pesquisador, por meio de contatos telefônicos ou mensagem eletrônica.

A pesquisa de campo contou com a participação de 15 entrevistados. As entrevistas ocorreram no período compreendido entre novembro de 2012 e janeiro de 2013, na própria organização. A pesquisa de campo contou com a participação de 15 entrevistados. A duração média de cada entrevista foi de 27 minutos. O Quadro 1 apresenta as durações das entrevistas realizadas pelo autor.

Quadro 3 - Entrevistado, nível hierárquico, tempo médio da entrevista e número de visitas

\begin{tabular}{cccc}
\hline ENTREVISTADO & NÍVEL & TEMPO MÉDIO DE & NÚMERO DE \\
EIERÁRQUICO & ENTREVISTA & 1 \\
\hline Médico 1 & Estratégico & $23 \mathrm{~min}$ & 1 \\
Médico 2 & Estratégico/Tático & $15 \mathrm{~min}$ & 2 \\
Enfermeira & Estratégico/Tático & $35 \mathrm{~min}$ & 1 \\
Coordenador tecnologia da & Estratégico/Tático & $17 \mathrm{~min}$ & 3 \\
informação & Estratégico/Tático & $110 \mathrm{~min}$ & 3
\end{tabular}


Supervisora de enfermagem

Técnico de enfermagem 1

Técnico de enfermagem 2

Técnico de enfermagem 3

Recepcionista

Farmacêutica

Supervisora da portaria

Supervisora de atendimento

Supervisora de convênios

Supervisora de limpeza
Estratégico/Tático

Operacional

Operacional

Operacional

Operacional

Operacional

Tático

Tático

Tático

Tático

$\begin{array}{ll}60 \mathrm{~min} & 2 \\ 15 \mathrm{~min} & 1 \\ 10 \mathrm{~min} & 1 \\ 16 \mathrm{~min} & 1 \\ 20 \mathrm{~min} & 1 \\ 20 \mathrm{~min} & 1 \\ 20 \mathrm{~min} & 1 \\ 16 \mathrm{~min} & 1 \\ 18 \mathrm{~min} & 1 \\ 21 \mathrm{~min} & 1\end{array}$

$60 \mathrm{~min}$

2

1

1

1

1

1

1

Fonte: Pesquisa de campo (2013)

Todas as entrevistas foram executadas por um único pesquisador no respectivo local de trabalho de cada um dos entrevistados. Ao iniciar a entrevista, o pesquisador explicava, de maneira resumida, os objetivos e a forma de condução da entrevista. Um roteiro de entrevista foi aplicado junto a alguns funcionários. Devido o caráter exploratório da pesquisa, houve certo grau de liberdade para o entrevistado discorrer sobre os temas que ele julgava relevantes. Em determinados momentos da entrevista, o pesquisador fazia perguntas de natureza aberta, para explorar temas e para confirmar algumas questões apresentadas.

\section{Apresentação e análise de resultados}

\subsection{O caso da Clínica Alfa}

A Clínica Alfa, fundada em 1994, é hoje um centro de referência no estado de Minas Gerais pela competência e humanização. É especializada na prevenção e no tratamento das doenças oncológicas. Mudou-se para sede atual em 2002. Suas instalações foram projetadas de forma humanizada, para gerar conforto aos pacientes e seus familiares, médicos e colaboradores.

Existem 14 consultórios médicos localizados, em quatro andares, e consultórios de quimioterapia, em dois andares. Cada consultório dispõe de salas de medicação com 30 leitos com área de televisão, convivência, boxe individualizado e ambiente para tratamento oncológico pediátrico. Há também uma lanchonete, um estacionamento e uma central de atendimento para agendamento de consultas e prestação de informações aos pacientes.

Constatou-se que a Clínica Alfa investe constantemente em infraestrutura, conhecimento e qualidade. Uma vez que a mesma obteve diversas certificações. Nesta direção, a Figura 2 mostra a linha do tempo com todos os Sistemas de Qualidade implantados pela empresa. 
Figura 2 - Linha do tempo das certificações da Clínica Alfa

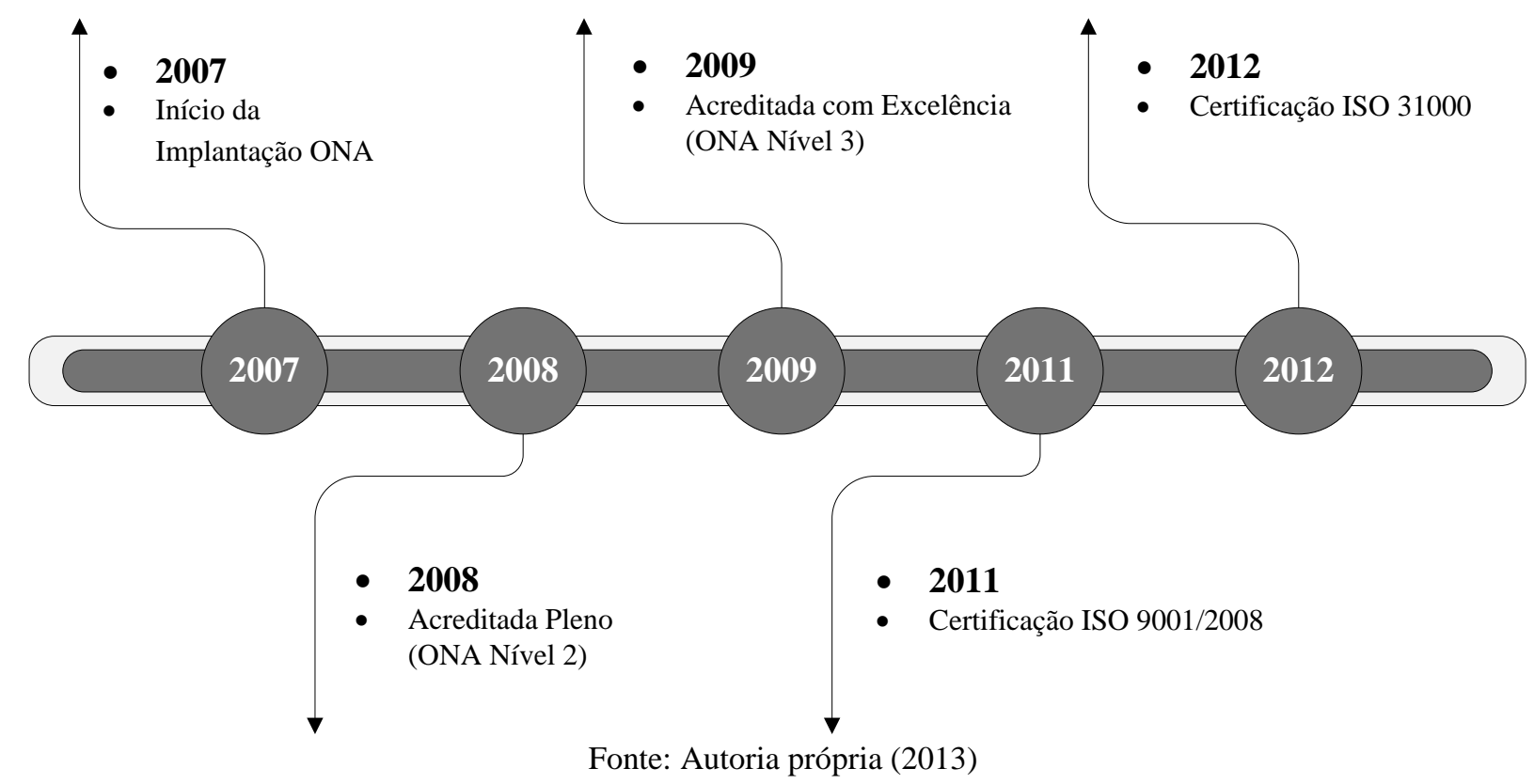

A empresa conta com 80 colaboradores. Há uma equipe multidisciplinar com 28 especialistas: oncologia (17), hematologia (5), nutrição (2), oncopediatria (1), clínica da dor (2) e psicologia (1).

Após a realização das entrevistas, estas foram transcritas e analisadas. Os resultados são apresentados nas subseções seguintes. Estas foram agrupadas conforme os três principais tipos de sinais: funcionais, mecânicos e humanos. Estas subseções retratam como os funcionários percebem a criação e entrega de cada um dos diferentes tipos de sinais ao cliente.

\subsection{Sinais funcionais: atendendo às expectativas do cliente}

Os valores e estratégias fundamentais da Clínica Alfa são "o calor humano, a transparência, o foco no cliente, a melhoria contínua de resultados e a prática médica colaborativa". Estes contribuem nitidamente para que ela apresente fortes sinais funcionais. O modelo de serviço em equipe sugere a sensação de a Clínica estar coordenando recursos para prestar o melhor tratamento possível. Com efeito, a "união de forças" serve como um poderoso sinal funcional. Os investimentos em sistemas e infraestrutura necessários à prestação de uma assistência médica integrada, rápida e eficiente, também transmitem aos pacientes e aos seus familiares que os acompanham a funcionalidade da Clínica. "Temos aqui na Comissão de Cuidado Multidisciplinar cujo objetivo é aumentar a integração entre profissionais de várias especialidades. Isso gera maior segurança e confiabilidade aos pacientes" destaca a supervisora de qualidade.

Ademais, os prontuários médicos e prescrições eletrônicas da Clínica Alfa - integrados e cumulativos - buscam demonstrar a confiança dos pacientes, como se pode ver neste comentário feito pela supervisora de enfermagem: "Tudo que a gente quer é trazer mais confiabilidade, 
segurança, transparência e controle de todo o processo de manipulação do medicamento e da checagem". O sistema informatizado passa segurança para a equipe e ajuda no trabalho diário. "É muito simples trabalhar com a checagem eletrônica. O uso da tecnologia vem, sem dúvida, ser uma ferramenta eficaz e complementar nos métodos de segurança já existentes na clínica, dando ainda mais garantias de sucesso no tratamento", relata a enfermeira.

A instituição acredita ainda que constantes investimentos na formação de médicos e de profissionais da saúde também podem contribuir para disseminação da competência na prestação do serviço. A Clínica Alfa realiza todos os anos uma série de reuniões científicas e incentivam participações em congressos especializados, com o propósito de debater as atualizações mais recentes do tratamento de vários tipos de câncer e de definir quais seriam as formas de tratamento mais adequadas para os pacientes da clínica. Segundo o coordenador do projeto, as reuniões são de enorme importância, porque contribuem para a atualização e interação entre profissionais da área:

O resultado tem sido extremamente positivo. Os profissionais relatam que a qualidade das apresentações contribui de forma significativa para o aprendizado contínuo. Dessa forma, a iniciativa permite que a Clínica Alfa continue a ser instituição de ponta e referência nacional no tratamento dos pacientes com câncer (médico 1).

Apesar de todo este esforço, o médico 2 reconhece que é difícil demonstrar a competência técnica aos pacientes, porém a Clínica busca amenizar este efeito com o uso de critérios rigorosos de conduta médica. O discurso aponta ainda que o corpo clínico está atualizado com as práticas médicas modernas.

Realmente, é mais difícil que o paciente perceba a competência técnica do corpo clínico. Hoje, a gente tem critérios muito bem estabelecidos de como devem ser as condutas médicas, principalmente, baseada na medicina baseada em evidência, que tem inclusive publicações, livros textos, softwares, sites que são atualizados continuamente. E o principal hoje que está sendo percebido pelos prestadores de serviço é a busca pela criação de uma maneira de demonstrar os resultados ao paciente. Mostrar que em um determinado diagnóstico quantos por cento se tem de resolubilidade (médico 2).

Outro sinal funcional que busca explicitar a competência e, de certa forma, dá aos pacientes pistas da qualidade do serviço prestado ocorre por meio da distribuição de cartilhas sobre o tratamento a ser realizado.

Todo paciente, para iniciar o tratamento, passa por uma consulta com a enfermeira. Nós distribuímos cartilhas nesta consulta, que informa ao paciente os possíveis efeitos adversos, por que eles acontecem e maneiras de aliviar esses efeitos ou de impedir que eles apareçam. Então, é aí que o atendimento é individualizado. Cada caso, passamos tanto verbalmente, nesse primeiro momento, quanto por escrito às orientações ao longo do tratamento. Nas vindas do paciente aqui, a gente também reforça essas orientações de acordo com o que o paciente vai apresentando durante o tratamento. Então, na primeira consulta, na primeira vez que o paciente toma medicação, ele recebe essa cartilha com orientação da enfermagem. Os próprios técnicos de enfermagem também estão sempre reforçando, mostrando qual medicamento e o que ele pode sentir com aquele medicamento. Além disso, o paciente quando vai embora para casa, nós temos um procedimento chamado de "retroalimentação". Então, até o prazo de cinco dias, a gente liga para esse paciente (temos 
funcionários responsáveis por essa retroalimentação), que ligam para o paciente e perguntam como que o paciente está passando. Dependendo do que o paciente coloca, reforçam-se essas orientações por telefone até a próxima visita do paciente à clínica (supervisora enfermagem).

A supervisora de enfermagem discorre também sobre o papel do cliente na coprodução do serviço prestado, devido ao "treinamento" proferido ao paciente no início do tratamento.

\footnotetext{
Apesar de cada paciente ter reações esperadas, cada um é de um jeito em relação às medicações. Informamos tudo isso aos pacientes. Como ele faz um tratamento ambulatorial e está em casa na maioria do tempo, ele deve saber reconhecer as reações e procurar assistência médica. Podem ser sinais esperados, mas se eles aparecerem, o paciente é orientado a procurar a assistência médica imediatamente. Eles possuem o número do celular do médico. Se não conseguem falar com o médico, devem procurar um pronto socorro ou hospital onde o médico dele trabalha (supervisora de enfermagem).
}

Caso o paciente tenha algum problema, ele sabe qual o procedimento deverá realizar, pois o mesmo já recebeu várias instruções. Como os clientes são educados para desenvolvimento de algumas capacidades necessárias para a execução de uma tarefa estes acabam contribuindo para a entrega de um serviço de qualidade (ZEITHAML; BITNER; GREMLER, 2011). Isso aumenta o grau de aceitação do papel de "coprodutor" pelo cliente. Algo necessário para a obtenção de um resultado positivo (BENDAPUDI; LEONE, 2003).

Ao capacitar o cliente para a execução de algumas tarefas, a Clínica Alfa faz com que o paciente se sinta seguro, diminuindo o sentimento de perda de controle sobre os resultados (BENDAPUDI; LEONE, 2003; DUHACHEK, 2005).

\subsection{Sinais mecânicos: influenciando as primeiras impressões, expectativas e valores}

Os sinais mecânicos são importantes no âmbito dos serviços de saúde (BERRY; SELTMAN; 2010). Com efeito, a assistência médica é um serviço incomum sob muitos aspectos, incluindo o próprio estresse que provoca nos clientes. Ser um paciente, geralmente, é algo não desejado na condição de consumidor. Os estresses que acometem os pacientes costumam decorrer de suas enfermidades ou ferimentos, podendo envolver dor, redução da capacidade física, ansiedade quanto a realização de exames médicos ou procedimentos agendados e incerteza em relação ao futuro. No entanto, uma dose considerável de estresse pode também advir das instalações onde é prestada a assistência. Neste sentido, os hospitais podem ser intimidantes, barulhentos, desprovidos de apoio emocional, desligados da natureza e aprisionadores (ULRICH, 1991).

A assistência médica não deveria ser desacoplada do ambiente em que é prestada. Haja vista a capacidade do ambiente em proporcionar uma série de oportunidades para tranquilizar os pacientes (e seus familiares), elevar-lhes o moral e despertar a sensação de cura (BERRY; SELTMAN; 2010). Seguindo esta visão, a filosofia que embasa o projeto das instalações da Clínica Alfa tem por objetivo aliviar o estresse daqueles que utilizam seus prédios - pacientes, familiares e outros visitantes. 
A estrutura física aqui é encantadora, se comparada aos outros lugares. Os consultórios parecem consultórios de novela. Existe todo um trabalho aqui. Temos um arquiteto, temos um decorador. Assim o design de ambiente é diferenciado. Então, o cliente já consegue perceber isso por aí. Ele chega aqui, não tem a característica de um ambiente hospitalar, muitas vezes, até sombrio... aquela mesa de metal, aquela coisa assustadora. Ele chega ao consultório, ele tem uma decoração. Cada um com uma decoração diferente, cores alegres, vivas que potencializa o astral daquele cliente (supervisora de qualidade).

O objetivo dos arquitetos e designers da Clínica é criar espaços físicos que permitam mitigar o estresse de seus ocupantes, em vez de acentuá-los. Causar uma boa impressão inicial com os espaços públicos de uma instalação médica é importante; contudo, a parte atemorizante da experiência de um paciente se dá em espaços privados, como as salas de exame, de espera e cirúrgicas.

Existem duas salas de Medicação utilizadas pelos pacientes. A Sala de Medicação 1 é dividida em três ambientes: duas salas de convivência com poltronas e televisão e leitos em boxes individualizados. Este espaço promove a interação dos pacientes. A Sala de Medicação 2 possui leitos em boxes individualizados com música ambiente. "Nossa poltrona é toda acolchoada e de boa qualidade. O paciente consegue colocar as pernas para o alto e deitar na poltrona” destaca a supervisora da qualidade. Uma sensação de tranquilidade permeia o local. Não há barulho (existe uma grande placa pedindo silêncio).

Poucos pacientes experimentam níveis de medo e estresse comparáveis aos das crianças que visitam uma clínica médica. No esforço por acalmar e distrair seus pacientes pediátricos, a Clínica Alfa procede a um cuidadoso gerenciamento dos sinais visuais em suas instalações. Estas exibem paredes coloridas, com inúmeras ilustrações, que despertam um interesse visual, desvinculando do ambiente hospitalar.

Hoje, a Clínica Alfa possui dois quartos. Nós chamamos de apartamento de crianças. Então, lá têm um leiaute com decoração infantil, apesar de termos poucas crianças em atendimento. O quarto possui imagem colorida, desenho, lápis de cor, televisão isso tudo para tornar um ambiente mais acolhedor para a criança (supervisora de qualidade).

Grande parte da decoração é apresentada ao alcance da visão das crianças. A iluminação é esmaecida. $\mathrm{O}$ ambiente é projetado de modo a tranquilizar e subjugar as preocupações.

O número de crianças é muito pouco. É um número baixo. A própria oncologia pediátrica gira em torno de $3 \%$ a $5 \%$ dos tumores de adultos, então é bem pequeno. Temos no segundo andar os apartamentos. As crianças, a gente separa e deixa bem fechadinha [risos]. Nós temos lá dois apartamentos onde ficam as crianças e os pais. Permitimos mais de um acompanhante. Aí, eles ficam lá com as crianças. Mantemos a porta fechada. Temos uma televisão só para elas. A parede é toda desenhada. Temos brinquedos, lápis, coisas assim para que eles brinquem. Criança é muito tranquila. Ela chora, esperneia, ela grita na hora de furar, de puncionar, mas depois ela é muito transparente, muito tranquila. A criança, na maioria das vezes, ela é mais fácil de lidar do que adulto. É muito difícil para a criança, mas para os pacientes adultos, ao verem a criança, é também difícil. Então por isso nós separamos as crianças. Se os pacientes adultos observassem uma criança chorando, eles ficam todos apreensivos. A criança já gera esse sentimento. Nós ficamos consternados. Não é de dó, não, mas todo mundo fica mais sensibilizado (supervisora da enfermagem). 
Um local especialmente projetado pode relaxar e diminuir as preocupações dos pacientes (ZEITHAML; BITNER; GREMLER, 2011). A Clínica Alfa acredita que um ambiente físico humanizado influi muito na hora do tratamento. Por isso, cada detalhe dos quartos foi planejado para oferecer mais conforto e atenção aos pacientes. Desde as cores dos ambientes até a disposição das poltronas e boxes. Isso possibilita que a equipe de enfermagem possa prestar a melhor atenção a todos. Ainda, há uma preocupação por parte da Clínica Alfa da influência que os pacientes têm entre si no desempenho final do serviço. A separação das crianças em quartos diferenciados evita que pacientes adultos sejam afetados negativamente uns pelos os outros.

\subsection{Sinais humanos: superando as expectativas}

A interação humana na experiência de serviço enseja a oportunidade de transmitir aos clientes respeito e apreço e, ao fazê-lo, superar suas expectativas, fortalecer sua confiança e aprofundar a lealdade. Assim como a intensidade da mão de obra pode ocasionar a indesejada variabilidade em um serviço, pode também criar uma variabilidade desejável quando o prestador executa o serviço com incomum civilidade, cuidado, compromisso e desenvoltura. A percepção dos clientes quanto ao empenho dos prestadores revela ter uma influência particularmente forte sobre sua satisfação e lealdade.

Enquanto os sinais funcionais costumam ser mais importantes para satisfazer às expectativas dos clientes quanto a toda a espécie de serviços (porque a funcionalidade oferece a principal solução procurada), os sinais humanos, geralmente, são mais importantes para superar as expectativas dos clientes quanto aos serviços com forte caráter interativo e altamente dependentes da mão de obra (porque o modo de tratar o cliente é crucial para essas experiências, e um tratamento excelente pode gerar uma surpresa agradável). O elemento da surpresa agradável é necessário para a superação das expectativas, e a melhor ocasião para proporcioná-lo é quando os clientes interagem com os prestadores de serviço.

O relato a seguir mostra que a equipe de enfermagem da Clínica Alfa busca desempenhar o trabalho não apenas com competência, mas também com muito carinho, dedicação e cuidado com o outro.

É uma satisfação coordenar uma equipe que faz tudo com muita dedicação e amor. Contamos com profissionais qualificados, que possuem profundo conhecimento nos processos de enfermagem e no desenvolvimento de protocolos. A experiência em outros setores, como emergência e unidade intensiva de saúde, e o entrosamento entre o grupos também são essenciais para o sucesso do departamento (supervisora de enfermagem 1).

A técnica de enfermagem 1 define a profissão como uma mistura de companheirismo e comprometimento: 
É doação. É preciso doar de corpo e de alma. Trabalho com amor, carinho. O profissional fica mais humanizado ao ter contato com tantos pacientes, tantas histórias e tantos sentimentos (técnica de enfermagem 1).

No início, ela era responsável desde a diluição até a aplicação do medicamento: "Fazíamos tudo, e hoje somos responsáveis pela administração, já que tudo vem preparado pela farmacêutica", acrescenta. Para ela, o humor é fundamental. Tanto que antes de entrar na Clínica Alfa ela afirma que deixa todos os problemas do lado de fora. Ressalta que chega para trabalhar feliz, pois o bom serviço começa pelo bom humor. "Dessa forma, os pacientes ficam à vontade e sentem que a gente é amiga, companheira". A técnica de enfermagem 1 afirma que a enfermagem é como uma meta para ela, pois quanto mais pratica mais ela quer fazer melhor. Para isso, lê, participa de congressos e simpósios. "Faço o que eu gosto", conclui.

A primeira pessoa a compor a equipe foi a técnica de enfermagem 2 , que atua na Clínica desde os primórdios da organização. Nos 17 anos da Clínica Alfa, ela relata a paixão pelo que faz. Sua rotina compreende administrar medicação aos pacientes, ligar o soro, conferir os dados de cada um e, principalmente, ouvir e dar atenção a todos. Ela explica que, pelo fato de lidar sempre com a dor, tenta transmitir aos pacientes a ideia de que na vida tudo passa e que o importante é tentar construir tudo de novo. Da mesma forma pensa a enfermeira. "Este é, sem dúvida, o maior desafio da minha carreira. Sinto que a cada dia cresço profissionalmente e pessoalmente aqui dentro". Ela destaca que outra característica da equipe é a inquietude intelectual. Além dos treinamentos mensais internos, o departamento de enfermagem participa constantemente de congressos e simpósios nacionais e regionais da área.

A oportunidade de crescimento dentro da empresa também estimula o comprometimento e a atenção cuidadosa com os pacientes. "Quando o profissional gosta do que faz, fica mais fácil dar conta de todas as suas obrigações", explica a supervisora de enfermagem.

Verificou-se que este espírito acolhedor se faz também presente na recepção da instituição. Uma funcionária que está na Clínica Alfa desde 1995 relata o quanto gosta do trabalho que desempenha.

Gosto do que faço. Tenho muito prazer, porque aprendi com os médicos, sempre dedicados. Além disso, o agradecimento sincero de cada paciente é muito gratificante. Não tem dinheiro que pague todo o carinho que recebo (recepcionista).

Os relatos indicam a satisfação da equipe de Enfermagem com o que fazem no dia a dia de suas funções. Assim, todo esse entusiasmo pode ser transmitido aos pacientes, que, muitas vezes, estão fragilizados emocionalmente pela doença.

Às vezes, ele [o paciente] pensa o pior, porque o câncer tem esse peso. Há uma associação com a morte. Acabou! Não tem mais o que fazer'. Quando eu trago o atendimento humanizado, eu venho trazendo mais leveza para esse paciente. Eu consigo ajudar ele a passar por esse momento do tratamento de uma forma melhor (supervisora de qualidade). 
A supervisora de qualidade, quando indagada como percebe que desenvolve um tratamento diferenciado, elaborou a seguinte resposta.

\begin{abstract}
Pela forma de tratar o paciente e pelo retorno que temos do paciente. Ele deixa nítido que gosta daqui e que é feliz. O último dia do paciente nós enfeitamos o leito dele com balões. Todo mundo vê e sabe que aquele paciente com balãozinho está terminando o tratamento. Semana passada, a gente teve um paciente que fez um bolo enorme e trouxe para todos colaboradores, porque ele estava recebendo alta. São pequenas atitudes que você vê que o paciente está satisfeito com o atendimento. O próprio visual do paciente em si aqui é diferenciado. Você olha para ele assim e você não percebe que ele é um paciente oncológico. Ele não é um paciente debilitado, não é um paciente baixo astral. Claro que temos pacientes que não estão assim. Mas, no geral, são pacientes mais alegres que estão lutando pela vida. Sabe, eu vejo que os colaborados da Clínica Alfa conseguem contribuir para essa luta pela vida (supervisora de qualidade).
\end{abstract}

A estadia do paciente na Clínica é amenizada pela realização de diversas atividades, como exposições, apresentações de artistas e atividades da Trupe da Alegria (grupo formado por profissionais da Clínica, cuja função é alegrar e entreter os pacientes durante o período da medicação).

A Clínica Alfa realiza também gincanas, que conta com a integração dos colaboradores, médicos, pacientes, acompanhantes e representantes, que realizam diversas atividades focadas na solidariedade. Várias tarefas movimentam as gincanas. Em uma delas, realizada em 2010, cada equipe deveria levar duas atrações para os pacientes que estivessem nas salas de medicação. Entre as presenças, já estiveram cantores, jogadores de futebol, grupos de contadores de história, mágico, dança, corais, bandas e sorteios de brindes. Os campeonatos de totó, truco e buraco são realizados no horário de almoço. Dentre as atividades de responsabilidade social, as equipes visitaram asilos e creches. "Como resultado tivemos uma interação muito grande das equipes nas tarefas. O sucesso foi maior do que esperávamos", revela a supervisora de qualidade.

\title{
4.5. A sustentação dos sinais da qualidade
}

Os relatos dos diversos funcionários envolvidos no processo de entrega do serviço relevaram a preocupação dos mesmos na entrega dos sinais da qualidade propostos pelos autores Berry, Carbone, Haeckel, Lewis e Seltman. Esta subseção discute como estes sinais são sustentados pela organização.

Neste contexto, pode-se afirmar que os sinais da qualidade provêm da implementação dos diversos Sistemas de Gestão da Qualidade (ISO 9001, ISO 31000 e Certificação ONA) adotados pela Clínica Alfa. Estes sistemas permitem uma sistematização da gestão da qualidade, organizando assim os processos de planejamento, melhoria e controle da qualidade na organização. As certificações também servem como instrumentos para tangibilizar o nível de excelência em qualidade atingido pela empresa. 
Figura 3 - Iceberg da percepção da qualidade

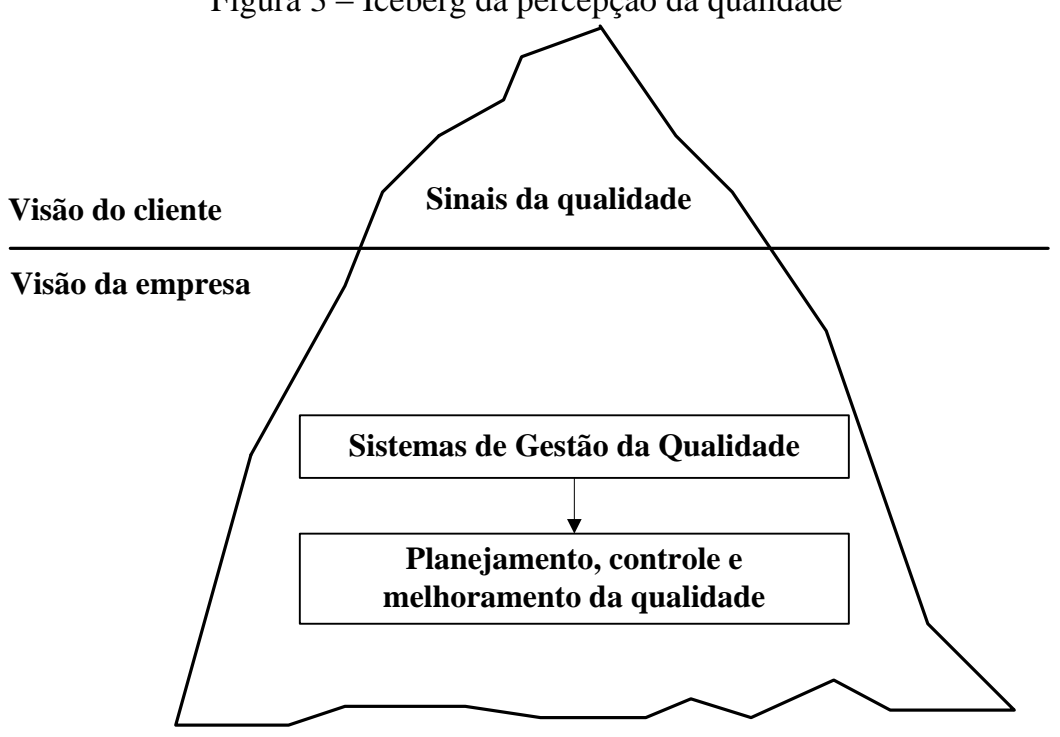

Fonte: Autoria própria (2013)

A Figura 3 retrata a relação entre os sinais da qualidade percebidos pelos clientes e sustentados pelos diversos sistemas de gestão da qualidade que auxiliam a organização na condução dos três grandes processos gerenciais de Gestão da Qualidade: planejamento, melhoramento e controle da qualidade.

Observou-se que os sinais funcionais são fortemente sustentados pela adoção de um sistema informatizado para a administração de medicamentos. Neste processo, a tecnologia desempenha papel preponderante na capacidade da empresa de prestar serviços de saúde de qualidade e com segurança a seus pacientes. Diversos investimentos foram destinados a tecnologias de computação, com foco especial no correto preparo e aplicação da medicação por meio da checagem eletrônica.

O uso da tecnologia vem, sem dúvida, ser uma ferramenta eficaz e complementar nos métodos de segurança já existentes na clínica, dando ainda mais garantias de sucesso ao tratamento (enfermeira).

Os sinais da qualidade mecânicos e humanos parecem advir muito mais do direcionamento estratégico adotado pela liderança do que dos sistemas da qualidade em si. A Trupe da Alegria, por exemplo, não é uma exigência de nenhum dos sistemas de gestão da qualidade. Entretanto, a Clínica Alfa acredita que tal ação reduz os impactos negativos ligados ao ambiente de cuidados em saúde, como dor, incerteza e medo. O projeto prepara a equipe para o relacionamento humanizado do recebimento dos pacientes e familiares ao término do atendimento.

A preocupação do sistema de gestão da qualidade (SGQ) no que tange aos sinais mecânicos é exposta em um dos depoimentos concedidos pela supervisora de enfermagem:

Não há a preocupação explicita dos sistemas de gestão da qualidade. Seguem-se todas as normas do Brasil dos países de segurança. Mas em termos da qualidade bens físicos do prédio, não. Nós não fizemos os apartamentos para as crianças por causa dos sistemas de gestão da qualidade. Existe uma prioridade na questão da satisfação. Você tem que ter níveis de satisfação e o reconhecimento de seu cliente, tanto interno quanto externo. Todo 
cliente preza pelo conforto e, de certa forma, vai obrigar a organização a ter equipamentos que trazem segurança, entretanto o sistema de gestão da qualidade não vai me falar que eu tenho que ter um computador de última geração ou se eu tenho um computador mais antigo de uma marca não muito boa. Mas se ele atende minha necessidade, tudo bem. Não se entra na questão da qualidade do medicamento, por exemplo. Se aquele laboratório está certificado e habilitado a comercializar em todo o Brasil, eu posso comprar. Se eu compro a melhor marca ou a pior marca, isso não é cobrado (supervisora de enfermagem).

A entrevistada deixa claro que não há requisitos explícitos que obriguem a organização a se preocupar com a questão da qualidade dos bens físicos da organização. A exigência do SGQ recai basicamente sobre os padrões brasileiros de cunho técnico. A criação dos apartamentos decorados, ambientes de descontração e leitos confortáveis provém dos direcionamentos formulados pelas lideranças da organização.

A Clínica Alfa realiza, desde 2008, uma pesquisa junto a seus pacientes e acompanhantes por meio de questionário para avaliação da satisfação. A pesquisa é realizada semestralmente e busca reforçar o conhecimento a respeito da satisfação dos clientes da Clínica Alfa, mensurando o valor percebido por eles nos serviços prestados.

Tabela 1 - Nível de satisfação dos pacientes

\begin{tabular}{|c|c|c|c|c|c|c|c|c|c|}
\hline & $\begin{array}{c}1^{\circ} \text { Sem. } \\
2008\end{array}$ & $\begin{array}{c}2^{\circ} \text { Sem. } \\
2008\end{array}$ & $\begin{array}{c}1^{\circ} \text { Sem. } \\
2009\end{array}$ & $\begin{array}{c}2^{\circ} \text { Sem. } \\
2009\end{array}$ & $\begin{array}{c}1^{\circ} \text { Sem. } \\
2010\end{array}$ & $\begin{array}{c}2^{\circ} \text { Sem. } \\
2010\end{array}$ & $\begin{array}{l}1^{\circ} \text { Sem. } \\
2011\end{array}$ & $\begin{array}{c}2^{\circ} \text { Sem. } \\
2011\end{array}$ & $\begin{array}{l}1^{\circ} \text { Sem. } \\
2012\end{array}$ \\
\hline Indice satisfação global & $81,05 \%$ & $89,16 \%$ & $88,45 \%$ & $92,81 \%$ & $91,39 \%$ & $91,77 \%$ & $86,30 \%$ & $86,88 \%$ & $97,27 \%$ \\
\hline Quesito melhor avaliado & Limpeza & Recepção & $\begin{array}{l}\text { Equipe } \\
\text { Médica }\end{array}$ & $\begin{array}{l}\text { Equipe } \\
\text { Médica }\end{array}$ & Enfermagem & Limpeza & Limpeza & Enfermagem & Enfermagem \\
\hline Quesito pior avaliado & Distração & $\begin{array}{l}\text { Atendimento } \\
\text { telefônico }\end{array}$ & $\begin{array}{l}\text { Atendimento } \\
\text { telefônico }\end{array}$ & $\begin{array}{l}\text { Atendimento } \\
\text { telefônico }\end{array}$ & Estrutura & $\begin{array}{l}\text { Atendimento } \\
\text { telefônico }\end{array}$ & $\begin{array}{l}\text { Atendimento } \\
\text { telefônico }\end{array}$ & $\begin{array}{l}\text { Atendimento } \\
\text { telefônico }\end{array}$ & $\begin{array}{l}\text { Equipe } \\
\text { Médica }\end{array}$ \\
\hline
\end{tabular}

Fonte: Pesquisa de campo (2013)

Os participantes respondem às alternativas atribuindo notas em uma escala de cinco pontos (modelo Likert). Os quesitos avaliados pelo questionário são atendimento na portaria, atendimento na recepção, atendimento na enfermagem, estrutura do ambiente, limpeza, atendimento telefônico, equipe médica, recursos de distração, atendimento da psicóloga e atendimento pela nutricionista que avaliam o serviço de forma global. Os resultados apresentados apontam a existência de um alto grau de satisfação dos clientes.

\section{Considerações finais}

Ao interagirem com qualquer organização, os clientes têm uma experiência de serviço, seja pessoalmente, por telefone, pela internet ou por outros meios de comunicação. Esta experiência é cheia de mensagens que impactam a forma como os clientes se sentem, bem como contam uma "história" sobre o serviço que a empresa fornece. Tais mensagens provêm de vários sinais, que os clientes percebem quando consideram a possibilidade de comprar um serviço. A implicação primordial disso é: será que os gestores conhecem os verdadeiros sinais que sua empresa está emitindo? Os clientes estão experimentando e construindo a história desejada pela organização? 
O objetivo deste trabalho foi apresentar uma nova visão sobre as experiências dos clientes nas organizações de serviços de saúde. Buscou-se construir uma linguagem e uma estrutura para explicitar as dimensões que formam a "experiência do cliente". Com este intuito, pretendeu-se esclarecer como as práticas adotadas pela organização se relacionam com as dimensões propostas.

Evidenciou-se como cada categoria de sinais desempenha papéis diferentes na criação da experiência de serviço para os clientes. Os sinais funcionais são essenciais, pois são parte fundamental do serviço. Sem sinais funcionais não há serviço. Sinais mecânicos podem despertar o interesse do cliente, no entanto estimulam suas expectativas e o julgamento. Para certos serviços, os sinais humanos apresentam a melhor oportunidade para exceder as expectativas dos clientes. Eles oferecem a melhor oportunidade para a ocorrência da surpresa agradável. Consequentemente, auxiliam na construção de estratégias que visem ao encantamento do cliente. A interação humana na experiência de serviço oferece a oportunidade de aprofundar a ligação emocional dos clientes com empresa. Por tudo isso, pode-se afirmar que os sinais devem ser adequadamente orquestrados pela gerência para que a qualidade dos serviços seja obtida. Para tanto, torna-se fundamental a compreensão do serviço na perspectiva da experiência vivenciada e desejada pelos clientes. Nesta direção, a organização precisa conhecer tudo que os clientes enxergam, ouvem, tocam, cheiram, provam, interagem, fazem e, acima de tudo, sentem.

Um ponto de destaque diz respeito à sustentação dos sinais da qualidade permitida por sistemas de gestão da qualidade, como ISO e a Acreditação, desenvolvidas pela Clínica Alfa. Percebe-se que a visão da qualidade da empresa permite enfatizar, principalmente, os aspectos funcionais da prestação do serviço. Já os sinais mecânicos e humanos parecem ser reflexos do posicionamento que lideranças da empresa têm a respeito da prestação de serviço de qualidade para seus clientes.

Devem-se registrar algumas limitações do trabalho. O problema tratado neste trabalho abrange o contexto de saúde, especificamente, oncologia. Dada a escassez de pesquisas brasileiras sobre o tema, praticamente toda a literatura utilizada é internacional, com destaque para autores norte-americanos. Por fim, o método de caso não permite a generalização dos resultados para todas as clínicas privadas brasileiras.

\section{Abstract}

Each costumer builds a service experience that can be decomposed by several others small experiments. Each one transmits many messages that impact how the customers feel about the service delivered. These messages can be understood like "clues of quality" that are perceived by customers during and after the delivery of the service. Referring to the importance of these clues for delivering a quality service, this paper aims to understand how the clues are constructed of quality 
in health care organizations that work with especially high pattern. In this direction, the paper analyzed many actions undertaken by managers and employees of an oncology clinical treatment prominent sector for creation of these clues. The paper pointed out the importance of Quality Management Systems for the creation of functional clues, important for service reliability. However, it was found that the creation of human and mechanical clues were fruits of the initiatives of company have pierced, largely, the requirements of Management Systems implemented.

Key-words: clues of quality; health quality; quality.

\section{Referências}

ANTUNES, F. L. Implantação do processo de acreditação baseado no manual das organizações prestadoras de serviços hospitalares da ONA: um estudo de caso em um hospital de grande porte, 2002. Dissertação (Mestrado em Engenharia de Produção), Universidade Federal do Rio Grande do Sul, 2002.

ASSOCIAÇÃO BRASILEIRA DE NORMAS TÉCNICAS. ISO 9001: 2008: Sistema de gestão da qualidade requisitos. Rio de Janeiro: ABNT, 2008.

BENDAPUDI, N.; BERRY, L. L.; FREY, K. A.; PARISH, J. T.; RAYBURN, W. L. Patients' perspectives on ideal physician behaviors, Mayo Clinic Proceedings, v. 81, 338-344, 2006. crossref

BENDAPUDI, N.; LEONE, R. P. Psychological implications of customer participation in co-production. Journal of marketing, p. 14-28, 2003. crossref

BERRY, L. L.; CARBONE, L. P. Build loyalty through experience management. Quality progress, v. 40, n. 9, p. 26, 2007.

BERRY, L. L.; SELTMAN, K. D. Lições de gestão da Clínica Mayo: por dentro de uma das mais admiradas organizações de serviços do mundo. Porto Alegre: Bookman, 2010.

BERRY, L. L.; WALL, E. A.; CARBONE, L. P. Service clues and customer assessment of the service experience: lessons from marketing. The Academy of Management Perspectives, v. 20, n. 2, p. 43-57, 2006. crossref

BERRY, L. L; BENDAPUDI, N. Health care: a fertile field for service research. Journal of Service Research, v. 10, n. 2, p. 111-122, 2007. crossref

BERRY, L. L; LAMPO, S. S. Brand in labour-intensive services. Business Strategy Review, v. 15, n. 1, p. 18-25, 2004. crossref

BERRY, L.L.; MIRABITO, A. M.; BERWICK, D.M. A health care agenda for business. MIT Sloan Management Review, v. 45, n. 4, p. 56-64, 2004.

BRYMAN, A. Research methods and organization studies. London: Routledge, 1989. crossref

BURKE, J. P. Infection control—a problem for patient safety. New England Journal of Medicine, v. 348, n. 7, p. 651656, 2003. crossref

CARBONE, L. Clued in: how to keep customers coming back again and again. New York: Finacianal Times Press, 2004.

CARBONE, L. P.; HAECKEL, S. H. Engineering customer experiences. Marketing Management, p. 8-19, 1994.

CARVALHO, M. M.; PALADINI, E. P. Gestão da qualidade teoria e casos. Rio de Janeiro: Elsevier Campus, 2006. CHASE, R. B.; APTE, U. M. A history of research in service operations: What's the big idea? Journal of Operations Management, v. 25, n. 2, p. 375-386, mar. 2007. crossref

CHASE, R. B.; STEWART, D M. Make your service fail-safe. Sloan Management Review, v. 35, n. 3, p. 35-44, 
1994.

DUHACHEK, A. Coping: a multidimensional, hierarchical framework of responses to stressful consumption episodes. Journal of Consumer Research, v. 32, n. 1, p. 41-53, 2005. crossref

EISENHARDT, K. M. Building theories from case-study research. Academy of Management Review, v. 14, n. 4, 532 $550,1989$.

FITZSIMMONS, J. A; FITZSIMMONS, M. J. Administração de serviços: operações, estratégia e tecnologia de informação. Porto Alegre: Bookman, 2010.

GALlAGHER, T. H.; WATERMAN, A. D.; EBERS, A. G.; FRASER, V. J.; LEVINSON, W. Patients' and physicians' attitudes regarding the disclosure of medical errors. JAMA: The Journal of the American Medical Association, v. 289, n. 8, p. 1001-1007, 2003. crossref

HAECKEL, S. H.; CARBONE, L. P.; BERRY, L. L. How to lead the customer experience. Marketing Management, v. 12 , n. 1 , p. 18-23, 2003.

HENDRICH, A.; FAY, J.; SORRELLS, A. Courage to heal: comprehensive cardiac critical care. Healthcare Design, p. $11-13,2002$.

KAHN, B. E.; LUCE, M. F. Understanding high-stakes consumer decisions: mammography adherence following falsealarm test results. Marketing Science, v. 22, n. 3, p. 393-410, 2003. crossref

KOHN, L. T.; CORRIGAN, J.; DONALDSON, M. S. To err is human: building a safer health system. Washington DC: National Academy Press, 2000.

LOVELOCK, C. H.; WIRTZ, J. Marketing de serviços: pessoas, tecnologia e resultados. São Paulo: Pearson Prentice Hall, 2008.

MORRIS, J. A.; FELDMAN, D. C. The dimensions, antecedents, and consequences of emotional labor. Academy of Management Review, p. 986-1010, 1996.

ORGANIZAÇÃO MUNDIAL DE SAÚDE (OMS). World health statistics 2010. Geneva: OMS, 2010.

ORGANIZAÇÃO NACIONAL DE ACREDITAÇÃO (ONA). Disponível em: <http:// www.ona.org.br >. Acesso em: 04 mar. 2013.

PAGANINI, J. M.; NOVAES, H. M. Garantia de qualidade: acreditaçäo de hospitais para América Latina e o Caribe. OPAS. Série Silos, v. 13, 1992.

PARASURAMAN, A.; ZEITHAML, V. A.; BERRY, Leonard L. SERVQUAL: a multiple-item scale for measuring consumer perceptions of service quality. Journal of Retailing, v. 64, n. 1, p. 12-40, 1988.

PEDROSO, M. C.; MALIK, A. M. As quatro dimensões competitivas da saúde. Harvard Business Review, v. 89, n. 3 , p. 54-63, 2011.

RAGHUNATHAN, R.; PHAM, M. T.; CORFMAN, K. P. Informational properties of anxiety and sadness, and displaced coping. Journal of Consumer Research, v. 32, n. 4, p. 596-601, 2006. cross ref

ULRICH, R. Effects of interior design on wellness: theory and recent scientific research. Journal of Healthcare Design, pp. 97-109, 1991.

WOOLF, S. H.; KUZEL, A. J.; DOVEY, S. M.; PHILLIPS, R. L. A string of mistakes: the importance of cascade analysis in describing, counting, and preventing medical errors. Annals of Family Medicine, v. 2, n. 4, p. 317-326, 2004. cross ref

YIN, R. K. Estudo de caso. Porto Alegre: Bookman, 2005.

ZEITHAML, V. A; BITNER, M. J.; GREMLER, D. D. Marketing de serviços: a empresa com foco no cliente. Porto Alegre: Bookman, 2011. 


\section{Dados dos autores}

Nome completo: Antonio Carlos Rodrigues

Filiação institucional: Faculdade de Ciências Econômicas da Universidade Federal de Minas Gerais

Departamento: Departamento de Ciências Administrativas (CAD)

Função ou cargo ocupado: Mestrando

Endereço completo para correspondência (bairro, cidade, estado, país e CEP): Avenida Antônio

Carlos, 6627 - Pampulha - Belo Horizonte - MG - Brasil - CEP 31270-901

Telefones para contato: (31)3409-7316 - ramal 7316

e-mail: tonimacr@gmail.com

\section{Nome completo: Noel Torres Júnior}

Filiação institucional: Faculdade de Ciências Econômicas da Universidade Federal de Minas Gerais

Departamento: Departamento de Ciências Administrativas (CAD)

Função ou cargo ocupado: Professor Adjunto

Endereço completo para correspondência (bairro, cidade, estado, país e CEP): Avenida Antônio

Carlos, 6627 - Pampulha - Belo Horizonte - MG - Brasil - CEP 31270-901

Telefones para contato: (31)3409-7316 - ramal 7316

e-mail: noel@ face.ufmg.br

Submetido em: 20/06/2013

Aceito em: 10/09/2014 